\title{
Is the Jump-Diffusion Model a Good Solution for Credit Risk Modeling? The Case of Convertible Bonds
}

\author{
$\operatorname{Tim} \mathrm{Xiao}^{1}$ \\ International Journal of Financial Markets and Derivatives, 4(1) 1-25, 2015
}

\begin{abstract}
This paper argues that the reduced-form jump diffusion model may not be appropriate for credit risk modeling. To correctly value hybrid defaultable financial instruments, e.g., convertible bonds, we present a new framework that relies on the probability distribution of a default jump rather than the default jump itself, as the default jump is usually inaccessible. As such, the model can back out the market prices of convertible bonds. A prevailing belief in the market is that convertible arbitrage is mainly due to convertible underpricing. Empirically, however, we do not find evidence supporting the underpricing hypothesis. Instead, we find that convertibles have relatively large positive gammas. As a typical convertible arbitrage strategy employs delta-neutral hedging, a large positive gamma can make the portfolio highly profitable, especially for a large movement in the underlying stock price.
\end{abstract}

${ }^{1}$ Email: tim yxiao@yahoo.com Url: https://finpricing.com/ 
Key Words: jump diffusion, convertible bond, convertible underpricing, convertible arbitrage, default time approach, default probability approach, asset pricing and credit risk modeling.

\section{Introduction}

A company can raise capital in financial markets either by issuing equities, bonds, or hybrids (such as convertible bonds). From an investor's perspective, convertible bonds with embedded optionality offer certain benefits of both equities and bonds - like the former, they have the potential for capital appreciation and like the latter, they offer interest income and safety of principal. The convertible bond market is of primary global importance.

There is a rich literature on the subject of convertible bonds. Arguably, the first widely adopted model among practitioners is the one presented by Goldman Sachs (1994) and then formalized by Tsiveriotis and Fernandes (1998). The Goldman Sachs' solution is a simple one factor model with an equity binomial tree to value convertible bonds. The model considers the probability of conversion at every node. If the convertible is certain to remain a bond, it is then discounted by a risky discount rate that reflects the credit risk of the issuer. If the convertible is certain to be converted, it is then discounted by the risk-free interest rate that is equivalent to default free.

Tsiveriotis and Fernandes (1998) argue that in practice one is usually uncertain as to whether the bond will be converted, and thus propose dividing convertible bonds into two components: a bond part that is subject to credit risk and an equity part that is free of credit risk. A simple description of this model and an easy numerical example in the context of a binomial tree can be found in Hull (2003).

Grimwood and Hodges (2002) indicate that the Goldman Sachs model is incoherent because it assumes that bonds are susceptible to credit risk but equities are not. Ayache, et al. (2003) conclude that the Tsiveriotis-Fernandes model is inherently unsatisfactory due to its unrealistic assumption of stock prices being unaffected by bankruptcy. To correct this weakness, Davis and Lischka (1999), Andersen and Buffum (2004), Bloomberg (2009), and Carr and Linetsky (2006) etc., propose a jump-diffusion model to explore 
defaultable stock price dynamics. They all believe that under a risk-neutral measure the expected rate of return on a defaultable stock must be equal to the risk-free interest rate. The jump-diffusion model characterizes the default time/jump directly.

The jump-diffusion model was first introduced by Merton (1976) in the market risk context for modeling asset price behavior that incorporates small day-to-day diffusive movements together with larger randomly occurring jumps. Over the last decade, people attempt to propagate the model from the market risk domain to the credit risk arena.

There are two primary types of models that attempt to describe default processes in the literature: structural models and reduced-form models. The structural models regard default as an endogenous event, focusing on the capital structure of a firm. The reduced-form models do not explain the event of a default endogenously, but instead characterize it exogenously as a jump process. Many practitioners in the credit trading arena have tended to gravitate toward the reduced-from models given their mathematical tractability and market consistency.

Zhou (1997), Hilberink and Rogers (2002), Chen and Kou (2009), etc. introduce the jump-diffusion mechanism into the structural models, while Davis and Lischka (1999), Andersen and Buffum (2004), and Bloomberg (2009), etc. add a default jump to the stock price dynamics. We refer to the formers as the structural jump-diffusion models and the latters as the reduced-form jump-diffusion models.

Although both the structural jump-diffusion model and the reduced-form model contain jumps, these jumps have different meanings: A jump in the structural jump-diffusion model corresponds to a sudden change in the asset value that may or may not cause the firm to default, whereas a jump in the reduced-form model represents the default event itself.

In this paper, we mainly discuss the reduced-form jump-diffusion models. At the heart of the jumpdiffusion models lies the assumption that the total expected rate of return to the stockholders is equal to the risk-free interest rate under a risk-neutral measure. 
Although we agree that under a risk-neutral measure the market price of risk and risk preferences are irrelevant to asset pricing (see Hull (2003)) and thereby the expectation of a risk-free ${ }^{2}$ asset grows at the risk-free interest rate, we are not convinced that the expected rate of return on a defaultable asset must be also equal to the risk-free rate. We argue that unlike market risk, credit risk actually has a significant impact on asset prices. This is why regulators, such as International Accounting Standards Board (IASB), Basel Committee on Banking Supervision (BCBS), etc. require financial institutions to report a credit value adjustment (CVA) in addition to the risk-free mark-to-market (MTM) value to reflect credit risk (see Xiao (2013)). By definition, a CVA is the difference between the risk-free value and the risky value of an asset/portfolio subject to credit risk. CVA implies that the risk-free value should not be equal to the risky value in the presence of default risk. As a matter of fact, we will prove that the expected return of a defaultable asset under a risk-neutral measure actually grows at a risky rate rather than the risk-free rate. This conclusion is very important for risky valuation.

Because of their hybrid nature, convertible bonds attract different type of investors. Especially, convertible arbitrage hedge funds play a dominant role in primary issues of convertible debt. In fact, it is believed that hedge funds purchase $70 \%$ to $80 \%$ of the convertible debt offered in primary markets. A prevailing belief in the market is that convertible arbitrage is mainly due to convertible underpricing (i.e., the model prices are on average higher than the observed trading prices) (see Ammann, et al (2003), Choi, et al. (2009), Loncarski, et al. (2009), etc.). However, Agarwal, et al. (2007) and Batta, et al. (2007) argue that the excess returns from convertible arbitrage strategies are not mainly due to underpricing, but rather partly due to illiquid. Calamos (2011) believes that arbitrageurs in general take advantage of volatility. A higher volatility in the underlying equity translates into a higher value of the equity option and a lower conversion premium. Multiple views reveal the complexity of convertible arbitrage, involving taking positions in the convertible bond and the underlying asset that hedges certain risks but leaves managers exposed to other risks for which they reap a reward.

\footnotetext{
${ }^{2}$ Here, risk-free means free of credit risk, but not necessarily of market risk
} 
This article makes a theoretical and empirical contribution to the study of convertible bonds. In contrast to the above mentioned literature, we present a model that is based on the probability distribution (or intensity) of a default jump (or a default time) rather than the default jump itself, as the default jump is usually inaccessible (see Duffie and Huang (1996), Jarrow and Protter (2004), etc).

We model both equities and bonds as defaultable in a consistent way. When a firm goes bankrupt, the investors who take the least risk are paid first. Secured creditors have the best chances of seeing the value of their initial investments come back to them. Bondholders have a greater potential for recovering some their losses than stockholders who are last in line to be repaid and usually receive little, if anything. The default proceedings provide a justification for our modeling assumptions: Different classes of securities issued by the same company have the same default probability but different recovery rates. Given this model, we are able to back out the market prices.

Valuation under our risky model can be solved by common numerical methods, such as, Monte Carlo simulation, tree/lattice approaches, or partial differential equation (PDE) solutions. The PDE algorithm is elaborated in this paper, but of course the methodology can be easily extended to tree/lattice or Monte Carlo.

Using the model proposed, we conduct an empirical study of convertible bonds. We obtain a data set from FinPricing (2015). The data set contains 164 convertible bonds and 2 years of daily market prices as well as associated interest rate curves, credit curves, stock prices, implied Black-Scholes volatilities and recovery rates.

The most important input parameter to be determined is the volatility for valuation. A common approach in the market is to use the at-the-money (ATM) implied Black-Scholes volatility to price convertible bonds. However, most liquid stock options have relatively short maturates (rarely more than 8 years). As a result, some authors, such as Ammann, et al. (2003), Loncarski, et al. (2009), Zabolotnyuk, et al. (2010), have to make do with historical volatilities. Therefore, we segment the sample into two sets according to the time to maturity: a short-maturity class $(0 \sim 8$ years $)$ and a long-maturity class ( $>8$ years). For the short-maturity class, we use the ATM implied Black-Scholes volatilities for valuation, whereas for 
the long-maturity class, we calculate the historical volatility as the annualized standard deviation of the daily log returns of the last 2 years and then price the convertible bond based on this real-world volatility.

The empirical results show that the model prices fluctuate randomly around the market prices, indicating the model is quite accurate. Our empirical evidence does not support a systematic underpricing hypothesis. A similar conclusion is reached by Ammann and Wilde (2008) who use a Monte-Carlo simulation approach. Moreover, market participants almost always calibrate their models to the observed market prices using implied convertible volatilities. Therefore, underpricing may not be the main driver of profitability in convertible arbitrage.

It is useful to examine the basics of the convertible arbitrage strategy. A typical convertible bond arbitrage employs delta-neutral hedging, in which an arbitrageur buys a convertible bond and sells the underlying equity at the current delta (see Choi, et al. (2009), Loncarski, et al. (2009), etc.). With delta neutral positions, the sign of Gamma is important. If Gamma is negative, the portfolio profits so long as the underlying equity remains stable. If Gamma is positive, the portfolio will profit from large movements in the stock price in either direction (see Somanath (2011)).

We study the sensitivities of convertible bonds and find that convertible bonds have relatively large positive gammas, implying that convertible arbitrage can make a profit on a large upside or downside movement in the underlying stock price. Since convertible bonds are issued mainly by start-up or small companies (while more established firms rely on other means of financing), the chance of a large movement in either direction is very likely. Even for very small movements in the underlying stock price, profits can still be generated from the yield of the convertible bond and the interest rebate for the short position.

The rest of this paper is organized as follows: The model is presented in Section 2. Section 3 elaborates the PDE approach; Section 4 discusses the empirical results. The conclusions are provided in Section 5. PDE implementation details, a binomial tree approach and a comparison of models are contained in the appendices. 


\section{$2 \quad$ Model}

Convertible bonds can be thought of as normal corporate bonds with embedded options, which enable the holder to exchange the bond asset for the issuer's stock. Despite their popularity and ubiquity, convertible bonds still pose difficult modeling challenges, given their hybrid nature of containing both debt and equity features. Further complications arise due to the frequent presence of complex contractual clauses, such as, put, hard call, soft call, and other path-dependent trigger provisions. Contracts of such complexity can only be solved by numerical methods, such as, Monte Carlo simulation, tree/lattice approaches, or PDE solutions.

From a practitioner's perspective, Monte Carlo is a "last resort" and "least preferred" method, whereas lattice or PDE approaches suffer from the curse of dimensionality: The number of evaluations and computational cost increase exponentially with the dimension of the problem, making it impractical to use in more than two dimensions.

Three sources of randomness exist in a convertible bond: the stock price, the interest rate, and the credit spread. As practitioners tend to eschew models with more than two factors, it is a legitimate question: How can we reduce the number of factors or which factors are most important? Grimwood and Hodges (2002) conduct a sensitivity study and find that accurately modeling the equity process appears crucial. This is why all convertible bond models in the market capture, at a minimum, the dynamics of the underlying equity price. Since convertible bonds are issued mainly by start-up or small companies (while more established firms rely on other means of financing), credit risk plays an important role in the valuation. Grimwood and Hodges (2002) further note that the interest rate process is of second order importance. Similarly, Brennan and Schwartz (1980) conclude that the effect of a stochastic interest rate on convertible bond prices is so small that it can be neglected. Furthermore, Ammann, et al. (2008) notice that the overall pricing benefit of incorporating stochastic interest rates would be very limited and would not justify the additional computational costs. For these reasons, most practical convertible models in the market do not take stochastic interest rate into account. 
We consider a filtered probability space $\left(\Omega, \mathcal{F},\left\{\mathcal{F}_{t}\right\}_{t \geq 0}, \mathcal{P}\right)$ satisfying the usual conditions, where $\Omega$ denotes a sample space, $\mathcal{F}$ denotes a $\sigma$-algebra, $\mathcal{P}$ denotes a probability measure, and $\left\{\mathcal{F}_{t}\right\}_{t \geq 0}$ denotes a filtration.

The risk-free stock price process can be described as

$$
d S(t)=r(t) S(t) d t+\sigma S(t) d W(t)
$$

where $S(t)$ denotes the stock price, $r(t)$ denotes the risk-free interest rate, $\sigma$ denotes the volatility, $W(t)$ denotes a Wiener process.

The expectation of equation (1) is

$$
E\left(d S(t) \mid \mathcal{F}_{t}\right)=r(t) S(t) d t
$$

where $E\left\{\bullet \mathcal{F}_{t}\right\}$ is the expectation conditional on the $\mathcal{F}_{t}$.

Equation (2) tells us that in a risk-neutral world, the expected return on a risk-free stock is the riskfree interest rate $r(t)$, i.e., the discounted stock price under the risk neutral measure is a martingale process.

Next, we turn to a defaultable stock. The defaultable stock process proposed by Davis and Lischka (1999), Andersen and Buffum (2004), and Bloomberg (2009), etc., is given by

$$
d S(t)=(r(t)+h(t)) S\left(t_{-}\right) d t+\hat{\sigma} S\left(t_{-}\right) d W(t)-S\left(t_{-}\right) d U(t)
$$

where $U(t)$ is an independent Poisson process with $d U(t)=1$ with probability $h(t) d t$ and 0 otherwise, $h(t)$ is the hazard rate or the default intensity, $S\left(t_{-}\right)$is the stock price immediately before any jump at time $t$. The expectation of $d U(t)$ is $E\left(d U(t) \mid \mathcal{F}_{t}\right)=h(t) d t$.

The expectation of equation (3) is given by

$$
E\left(d S(t) \mid \mathcal{F}_{t}\right)=(r(t)+h(t)) S(t) d t-S(t) h(t) d t=r(t) S(t) d t
$$

It is shown in equation (4) that the expected return of a defaultable stock under a jump-diffusion model also grows at the risk-free interest rate. Equation (3) is a simpler version of the Merton's Jumpdiffusion model where the number of jumps is 1 . 
The jump-diffusion model was first proposed in the context of market risk, which naturally exhibits high skewness and leptokurtosis levels and captures the so-called implied volatility smile or skew effects. Ederington and Lee (1993) find that the markets tend to have overreaction and underreaction to the outside news. The jump part of the model can be interpreted as the market response to outside news. If there is not any outside news, the asset price changes according to a geometric Brownian motion. Since the market price of risk and risk preferences are irrelevant to asset pricing within the market risk context, the expected rate of return to the stockholders is equal to the risk-free rate under a risk-neutral measure.

However, we wonder whether it is appropriate to propagate the jump-diffusion model directly from the market risk domain to the credit risk domain, as credit risk actually impacts the valuation of assets. This is why financial institutions are required by regulators to report CVA. In fact, we will show in the following derivation that the expected return of a defaultable asset under a risk-neutral measure is actually equal to a risky rate instead of the risk-free rate. This conclusion is very important for risky valuation.

The world of credit modeling is divided into two main approaches: structural models and reducedform (or intensity) models. The structural models regard default as an endogenous event, focusing on the capital structure of a firm. The reduced-form models do not explain the event of default endogenously, but instead characterize it exogenously as a jump process. In general, structural models are based on the information set available to the firm's management, such as the firm's assets and liabilities; while reducedform models are based on the information set available to the market, such as the firm's bond prices or credit default swap (CDS) premia. Many practitioners in the credit trading arena have tended to gravitate toward the reduced-from models given their mathematical tractability. The reduced-form models can be made consistent with the risk-neutral probabilities of default backed out from corporate bond prices or CDS spreads/premia.

In the reduced-form models, the stopping (or default) time $\tau$ of a firm is modeled as a Cox arrival process (also known as a doubly stochastic Poisson process) whose first jump occurs at default and is defined as, 


$$
\tau=\inf \left\{t: \int_{0}^{t} h\left(s, \Phi_{s}\right) d s \geq \Delta\right\}
$$

where $h(t)$ or $h\left(t, \Phi_{t}\right)$ denotes the stochastic hazard rate or arrival intensity dependent on an exogenous common state $\Phi_{t}$, and $\Delta$ is a unit exponential random variable independent of $\Phi_{t}$.

It is well-known that the survival probability from time $t$ to $s$ in this framework is defined by

$$
p(t, s):=P(\tau>s \mid \tau>t, Z)=\exp \left(-\int_{t}^{s} h(u) d u\right)
$$

The default probability for the period $(t, s)$ in this framework is defined by

$$
q(t, s):=P(\tau \leq s \mid \tau>t, Z)=1-p(t, s)=1-\exp \left(-\int_{t}^{s} h(u) d u\right)
$$

We consider a defaultable asset that pays nothing between dates $t$ and $T$. Let $V(t)$ and $V(T)$ denote its values at $t$ and $T$, respectively. Risky valuation can be generally classified into two categories: the default time approach (DTA) and the default probability (intensity) approach (DPA).

The DTA involves the default time explicitly. If there has been no default before time $T$ (i.e., $\tau>T$ ), the value of the asset at $T$ is $V(T)$. If a default happens before $T$ (i.e., $t<\tau \leq T$ ), a recovery payoff is made at the default time $\tau$ as a fraction of the market value ${ }^{3}$ given by $\varphi V(\tau)$ where $\varphi$ is the default recovery rate and $V(\tau)$ is the market value at default. Under a risk-neutral measure, the value of this defaultable asset is the discounted expectation of all the payoffs and is given by

$$
V(t)=E\left[\left(D(t, T) V(T) 1_{\tau>T}+D(t, \tau) \varphi V(\tau) 1_{\tau \leq T}\right) \mid \mathcal{F}_{t}\right]
$$

where $1_{Y}$ is an indicator function that is equal to one if $Y$ is true and zero otherwise, and $D(t, \tau)$ denotes the stochastic risk-free discount factor at $t$ for the maturity $\tau$ given by

$$
D(t, \tau)=\exp \left[-\int_{t}^{\tau} r(u) d u\right]
$$

\footnotetext{
${ }^{3}$ Here we use the recovery of market value (RMV) assumption.
} 
Although the DTA is very intuitive, it has the disadvantage that it explicitly involves the default time/jump. We are very unlikely to have complete information about a firm's default point, which is often inaccessible. Usually, valuation under the DTA is performed via Monte Carlo simulation.

The DPA relies on the probability distribution of the default time rather than the default time itself. We divide the time period $(t, T)$ into $n$ very small time intervals $(\Delta t)$ and assume that a default may occur only at the end of each very small period. In our derivation, we use the approximation $\exp (y) \approx 1+y$ for very small $y$. The survival and default probabilities for the period $(t, t+\Delta t)$ are given by

$$
\begin{aligned}
& \hat{p}(t):=p(t, t+\Delta t)=\exp (-h(t) \Delta t) \approx 1-h(t) \Delta t \\
& \hat{q}(t):=q(t, t+\Delta t)=1-\exp (-h(t) \Delta t) \approx h(t) \Delta t
\end{aligned}
$$

The binomial default rule considers only two possible states: default or survival. For the one-period ( $t, t+\Delta t$ ) economy, at time $t+\Delta t$ the asset either defaults with the default probability $q(t, t+\Delta t)$ or survives with the survival probability $p(t, t+\Delta t)$. The survival payoff is equal to the market value $V(t+\Delta t)$ and the default payoff is a fraction of the market value: $\varphi(t+\Delta t) V(t+\Delta t)$. Under a risk-neutral measure, the value of the asset at $t$ is the expectation of all the payoffs discounted at the risk-free rate and is given by

$$
V(t)=E\left\{\exp (-r(t) \Delta t)[\hat{p}(t)+\varphi(t) \hat{q}(t)] V(t+\Delta t) \mid \mathcal{F}_{t}\right\} \approx E\left\{\exp (-y(t) \Delta t) V(t+\Delta t) \mid \mathcal{F}_{t}\right\}
$$

where $y(t)=r(t)+h(t)(1-\varphi(t))=r(t)+c(t)$ denotes the risky rate and $c(t)=h(t)(1-\varphi(t))$ is called the (short) credit spread.

Similarly, we have

$$
V(t+\Delta t)=E\left\{\exp (-y(t+\Delta t) \Delta t) V(t+2 \Delta t) \mid \mathcal{F}_{t+\Delta t}\right\}
$$

Note that $\exp (-y(t) \Delta t)$ is $\mathcal{F}_{t+\Delta t}$-measurable. By definition, an $\mathcal{F}_{t+\Delta t}$-measurable random variable is a random variable whose value is known at time $t+\Delta t$. Based on the taking out what is known and tower properties of conditional expectation, we have 


$$
\begin{aligned}
V(t) & =E\left\{\exp (-y(t) \Delta t) V(t+\Delta t) \mid \mathcal{F}_{t}\right\} \\
& =E\left\{\exp (-y(t) \Delta t) E\left[\exp (-y(t+\Delta t) \Delta t) V(t+2 \Delta t) \mid \mathcal{F}_{t+\Delta t}\right] \mid \mathcal{F}_{t}\right\} \\
& \left.=E\left\{\exp \left(-\sum_{i=0}^{1} y(t+i \Delta t) \Delta t\right)\right) V(t+2 \Delta t) \mid \mathcal{F}_{t}\right\}
\end{aligned}
$$

By recursively deriving from $t$ forward over $T$ and taking the limit as $\Delta t$ approaches zero, the risky value of the asset can be expressed as

$$
V(t)=E\left\{\exp \left[-\int_{t}^{T} y(u) d u\right] V(T) \mid \mathcal{F}_{t}\right\}
$$

Using the DPA, we obtain a closed-form solution for pricing an asset subject to credit risk. Another good example of the DPA is the CDS model proposed by J.P. Morgan (1999).

The derivation of equation (15) takes into account all credit characteristics: possibility of a jump to default and recovery rate. It tells us that a defaultable asset under the risk-neutral measure grows at a risky rate. The risky rate is equal to a risk-free interest rate plus a credit spread. If the asset is a bond, the equation is the same as Equation (10) in Duffie and Singleton (1999), which is the market model for pricing risky bonds. The market bond model says that the value of a risky bond is obtained by discounting the promised payoff using the risk-free interest rate plus the credit spread ${ }^{4}$.

Under a risk-neutral measure the market price of risk and risk preferences are irrelevant to asset pricing (see Hull (2003)) and thereby the expectation of a risk-free asset grows at the risk-free interest rate. However, credit risk actually has a significant impact on asset prices. This is the reason that regulators, such as IASB and BCBS, require financial institutions to report a CVA in addition to the risk-free MTM value to reflect credit risk.

In asset pricing theory, the fundamental no-arbitrage theorems do not require expected returns to be equal to the risk free rate, but only that prices are martingales after discounting under the numeraire. For risk-free valuation, people commonly use a risk-free bond as the numeraire, whereas for risky valuation,

\footnotetext{
${ }^{4}$ There is a liquidity component in the bond spread. This paper, however, focuses on credit risk only.
} 
they should choose an associated risky numeraire to reflect credit risk. The expected return is that of the numeraire.

If a company files bankruptcy, both bonds and stocks go into a default status. In other words, the default probabilities for both of them are the same (i.e., equal to the firm's probability of default). But the recovery rates are different because the stockholders are the lowest priority in the list of the stakeholders in the company, whereas the bondholders have a higher priority to receive a higher percentage of invested funds. The default proceedings provide a justification for our modeling assumptions: Different classes of securities issued by the same company have the same default probability but different recovery rates.

According to equation (15), we propose a risky model that embeds the probability of the default jump rather than the default jump itself into the price dynamics of an asset. The stochastic differential equation (SDE) of a defaultable stock is defined as

$$
d S(t)=\left(r(t)+h(t)\left(1-\varphi_{s}(t)\right)\right) S(t) d t+\sigma S(t) d W(t)=y(t) S(t) d t+\sigma S(t) d W(t)
$$

where $\varphi_{s}$ is the recovery rate of the stock and $y(t)=r(t)+h(t)\left(1-\varphi_{s}(t)\right)$ is the risky rate.

For most practical problems, zero recovery at default (or jump to zero) is unrealistic. For example, the stock of Lehman Brothers fell 94.3\% on September 15, 2008 after the company filed for Chapter 11 bankruptcy. Similarly, the shares of General Motors (GM) plunged 32\% on June 1, 2009 after the firm initiated Chapter 11 bankruptcy. A good framework should flexibly allow people to incorporate different recovery assumptions into risky valuation.

Equation (16) is the direct derivation of equation (15). The formula allows different assumptions concerning recovery on default. In particular, $\varphi_{s}=0$ represents the situation where the stock price jumps to 0 , and $\varphi_{s}=1$ corresponds to the risk-free case. The expectation of equations (16) is

$$
E\left(d S(t) \mid \mathcal{F}_{t}\right)=\left(r(t)+h(t)\left(1-\varphi_{s}(t)\right)\right) S(t) d t
$$

Equation (17) says that the expected return of a stock subject to credit risk is equal to a risky rate rather than the risk-free rate. The risky rate reflects the compensation investors receive for bearing credit risk. 


\section{PDE Algorithm}

The numerical solution of our risky model can be obtained by either PDE methods, tree approaches, or Monte Carlo simulation. In this paper, we introduce the PDE procedure, but of course the methodology can be easily extended to the tree/lattice or Monte Carlo algorithms.

The defaultable stock price process is given by

$$
d S(t)=\left(r(t)-q(t)+h(t)\left(1-\varphi_{s}(t)\right)\right) S(t) d t+\sigma S(t) d W(t)=\mu(t) S(t) d t+\sigma S(t) d W(t)
$$

where $q(t)$ is the dividend and $\mu(t)=r(t)-q(t)+h(t)\left(1-\varphi_{s}(t)\right)$.

The valuation of a convertible bond normally has a backward nature since there is no way of knowing whether the convertible should be converted without knowledge of the future value. Only on the maturity date, the value of the convertible and the decision strategy are clear. If the convertible is certain to be converted, it behaves like a stock. If the convertible is not converted at an intermediate node, we are usually uncertain whether the continuation value should be treated as a bond or a stock, because in backward induction the current value takes into account the results of all future decisions and some future values may be dominated by the stock or by the bond or by both. Therefore, we arrange the valuation so that the value of the convertible at each node is divided into two components: a component of bond and a component of stock, i.e. $L(S, t)=G(S, t)+B(S, t)$ where $G(S, t)$ denotes the equity part of the convertible bond and $B(S, t)$ denotes the bond part of the convertible.

Suppose that $G(S, t)$ is some function of $S$ and $t$. Applying Ito Lemma, we have

$$
d G=\left(\mu S \frac{\partial G}{\partial S}+\frac{\partial G}{\partial t}+\frac{1}{2} \sigma^{2} S^{2} \frac{\partial^{2} G}{\partial S^{2}}\right) d t+\sigma S \frac{\partial G}{\partial S} d W
$$

Since the Wiener process underlying $S$ and $G$ are the same, we can construct the following portfolio so that the Wiener process can be eliminated.

$$
X=G-S \frac{\partial G}{\partial S}
$$


Therefore, we have

$$
d X=d G-\frac{\partial G}{\partial S} d S=\left(\frac{\partial G}{\partial t}+\frac{1}{2} \sigma^{2} S^{2} \frac{\partial^{2} G}{\partial S^{2}}\right) d t
$$

In contrast to all previous studies, we believe that the defaultable equity should grow at the risky rate of the equity including dividends, whereas the equity part of the convertible bond should earn the risky rate of the equity excluding dividends, i.e.,

$$
\left(r+h\left(1-\varphi_{s}\right)\right) G d t-\left(r-q+h\left(1-\varphi_{s}\right)\right) \frac{\partial G}{\partial S} S d t=d X=\left(\frac{\partial G}{\partial t}+\frac{1}{2} \sigma^{2} S^{2} \frac{\partial^{2} G}{\partial S^{2}}\right) d t
$$

So that the PDE of the equity component is given by

$$
\frac{\partial G}{\partial t}+\frac{1}{2} \sigma^{2} S^{2} \frac{\partial^{2} G}{\partial S^{2}}+\left(r-q+h\left(1-\varphi_{s}\right)\right) S \frac{\partial G}{\partial S}-\left(r+h\left(1-\varphi_{s}\right)\right) G=0
$$

Similarly applying Ito Lemma to the bond part of the convertible $B(S, t)$, we obtain

$$
d B=\left(\mu S \frac{\partial B}{\partial S}+\frac{\partial B}{\partial t}+\frac{1}{2} \sigma^{2} S^{2} \frac{\partial^{2} B}{\partial S^{2}}\right) d t+\sigma S \frac{\partial B}{\partial S} d W
$$

Let us construct a portfolio so that we can eliminate the Wiener process as follows

$$
Y=B-S \frac{\partial B}{\partial S}
$$

Thus, we have

$$
d Y=d B-\frac{\partial B}{\partial S} d S=\left(\frac{\partial B}{\partial t}+\frac{1}{2} \sigma^{2} S^{2} \frac{\partial^{2} B}{\partial S^{2}}\right) d t
$$

The defaultable equity should grow at the risky rate of the equity including dividends, while the bond part of the convertible bond grows at the risky rate of the bond. Consequently, we have

$$
\left(r+h\left(1-\varphi_{b}\right)\right) B d t-\left(r-q+h\left(1-\varphi_{s}\right)\right) \frac{\partial B}{\partial S} S d t=d Y=\left(\frac{\partial B}{\partial t}+\frac{1}{2} \sigma^{2} S^{2} \frac{\partial^{2} B}{\partial S^{2}}\right) d t
$$

where $\varphi_{b}$ is the recovery rate of the bond.

The PDE of the bond component is

$$
\frac{\partial B}{\partial t}+\frac{1}{2} \sigma^{2} S^{2} \frac{\partial^{2} B}{\partial S^{2}}+\left(r-q+h\left(1-\varphi_{s}\right)\right) S \frac{\partial B}{\partial S}-\left(r+h\left(1-\varphi_{b}\right)\right) B=0
$$


Equations (23) and (28) are coupled through appropriate final and boundary conditions reflecting the terms and conditions of each individual convertible and need to be solved simultaneously. Convertible bonds often incorporate various additional features, such as call and put provisions.

The final conditions at maturity $T$ can be generalized as

$$
\begin{gathered}
G_{T}= \begin{cases}\eta S_{T}, & \text { if } \eta S_{T}>\min \left[P_{c}, \max \left(P_{p}, N+C\right)\right\rfloor \\
0, & \text { otherwise }\end{cases} \\
B_{T}=\left\{\begin{array}{cr}
\min \left\lfloor P_{c}, \max \left(P_{p}, N+C\right)\right\} & \text { if } \eta S_{T} \leq \min \left[P_{c}, \max \left(P_{p}, N+C\right)\right\rfloor \\
0, & \text { otherwise }
\end{array}\right.
\end{gathered}
$$

where $N$ denotes the bond principal, $C$ denotes the coupon, $P_{c}$ denotes the call price, $P_{p}$ denotes the put price and $\eta$ denotes the conversion ratio. The final conditions tell us that the convertible bond at the maturity is either a debt or an equity.

The upside constraints at time $t \in[0, T]$ are

$$
\left\{\begin{array}{lr}
G_{t}=\eta S_{t}, B_{t}=0 & \text { if } \eta S_{t}>\min \left[P_{c}, \max \left(P_{p}, \tilde{L}_{t}\right)\right] \\
G_{t}=0, B_{t}=P_{p} & \text { else if } \tilde{L}_{t} \leq P_{p} \\
G_{t}=0, B_{t}=P_{c} & \text { else if } \tilde{L}_{t} \geq P_{c} \\
G_{t}=\tilde{G}_{t}, B_{t}=\tilde{B}_{t} & \text { else }
\end{array}\right.
$$

where $\tilde{L}_{t}=\tilde{B}_{t}+\tilde{G}_{t}$ is the continuation value of the convertible bond, $\tilde{B}_{t}$ is the continuation value of the bond component and $\tilde{G}_{t}$ is the continuation value of the equity component. Equation (31) says that the convertible is either in the continuation region or one of the three constraints (called, put or converted). One can use finite difference methods to solve the PDEs (23) and (28) for the price of a convertible bond.

\section{Empirical results}

This section presents the empirical results. We use two years of daily data from September 10, 2010 to September 10, 2012, i.e., a total of 522 observation days. This proprietary data are obtained from an investment bank. They consist of convertible bond contracts, market observed convertible prices, interest rate curves, credit curves, stock prices, implied Black-Scholes volatilities, and recovery rates. 


\section{Figure 1. Histogram of convertible bonds by time to maturity}

This histogram divides the convertible bonds in our sample, as of September 10, 2012, into different bins according to the time to maturity. The $\mathrm{x}$-axis represents the maturity in years and the $y$-axis represents the number of convertibles in each bins. A maturity bin of $n$ covers contracts with a time to maturity ranging from $n-1$ years to $n$ years.

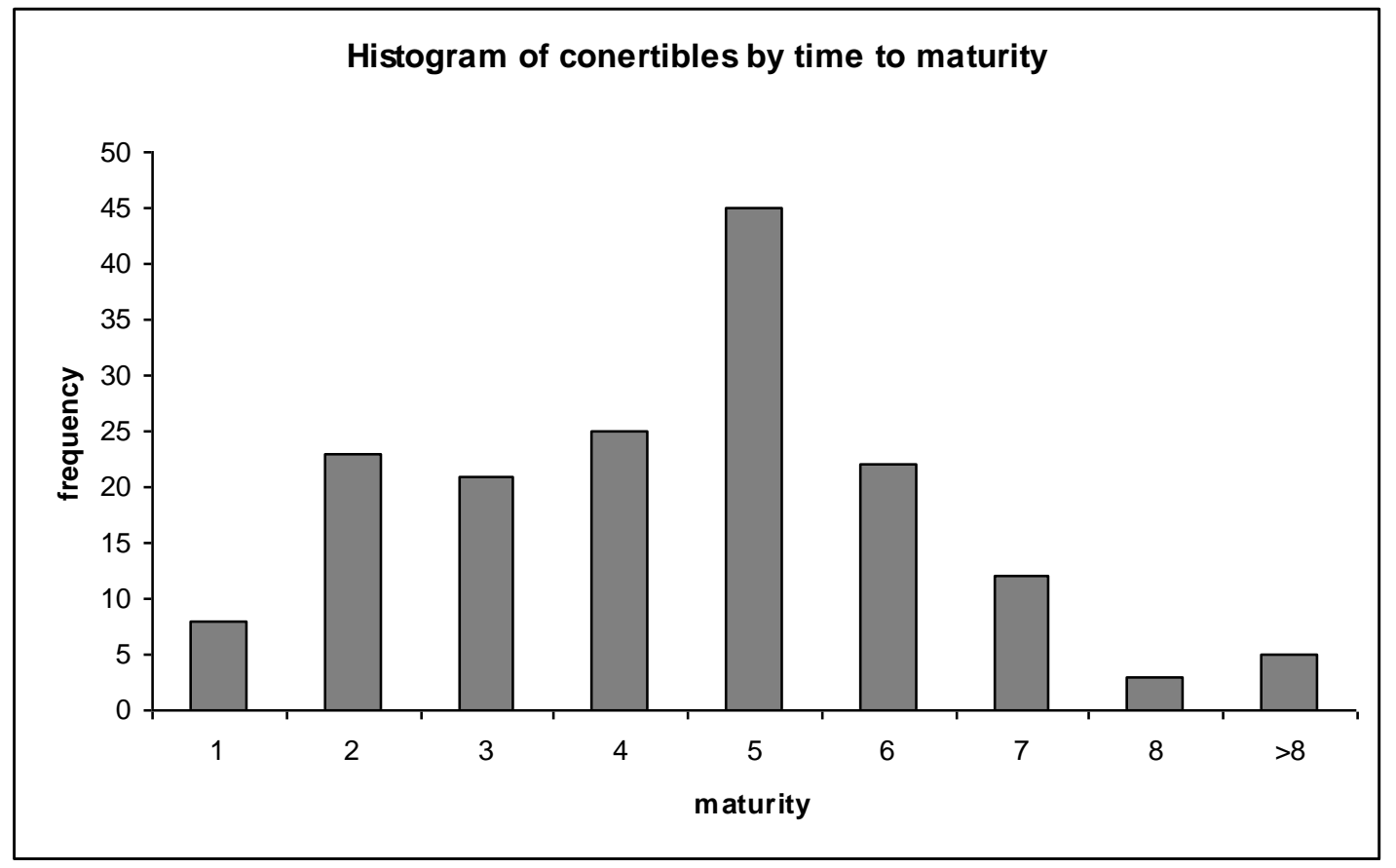

We only consider the convertibles outstanding during the period and with sufficient pricing information. As a result, we obtain a final sample of 164 convertible bonds and a total of $164 \times 522=$ 85,608 observations. None of the convertibles in this sample actually defaulted during the time window.

As of September 10, 2012, the sample represents a family of convertible bonds with a time to maturity ranging from 2 months to 36.6 years, and has an average remaining maturity of 4.35 years. The histogram of contracts on September 10, 2012 for various maturity classes is given in Figure 1.

Convertible bond prices observed in the market will be compared with theoretical prices under different volatility assumptions. The sample is segmented into two sets according to the time to maturity: a short-maturity class $(0 \sim 8$ years $)$ and a long-maturity class ( $>8$ years $)$. We first select a convertible bond 
from each group: a 7-year (or 5-year outstanding) contract and a 20-year (or 17-year outstanding) contract shown in Table 1.

\section{Table 1. Convertible Bonds}

We hide the issuer names according to the security policy of the investment bank, but everything else is authentic. In the market, either a conversion price or a conversion ratio is given for a convertible bond, where conversion ratio $=($ face value of the convertible bond $) /($ conversion price $)$.

\begin{tabular}{|c|c|c|}
\hline Convertible bond & Case 1 (a 7-year convertible) & Case 2 (a 20-year convertible) \\
\hline Issuer & $X$ company & $Y$ company \\
Notional of bond & 100 & 100 \\
Annual coupon rate & 2.625 & 5.5 \\
Payment frequency & Semiannual & Semiannual \\
Issuing date & June 9, 2010 & June 15, 2009 \\
Maturity date & June 15,2017 & June 15,2029 \\
Conversion price & 30.288 & 13.9387 \\
Currency & USD & USD \\
Day count & $30 / 360$ & $30 / 360$ \\
Business day convention & Following & Following \\
Put price & - & 100 at June 20, 2014 \\
\hline
\end{tabular}

Let valuation date be September 10, 2012. An interest rate curve is the term structure of interest rates, derived from observed market instruments that represent the most liquid and dominant interest rate products for certain time horizons. Normally the curve is divided into three parts. The short end of the term structure is determined using the London Interbank Offered Rates (LIBOR). The middle part of the curve is constructed using Eurodollar futures that require convexity adjustments. The far end is derived using mid swap rates. The LIBOR-future-swap curve is presented in Table 2. We bootstrap the curve and get the continuously compounded zero rates. 
Table 2: USD LIBOR-Future-Swap Curve

This table displays the closing prices as of September 10, 2012.

\begin{tabular}{|c|c|}
\hline Instrument Name & Price \\
\hline September 19, 2012 LIBOR & $0.6049 \%$ \\
\hline September 2012 Eurodollar 3 month & 99.6125 \\
\hline December 2012 Eurodollar 3 month & 99.6500 \\
\hline March 2013 Eurodollar 3 month & 99.6500 \\
\hline June 2013 Eurodollar 3 month & 99.6350 \\
\hline September 2013 Eurodollar 3 month & 99.6200 \\
\hline December 2013 Eurodollar 3 month & 99.5900 \\
\hline March 2014 Eurodollar 3 month & 99.5650 \\
\hline 2 year swap rate & $0.3968 \%$ \\
\hline 3 year swap rate & $0.4734 \%$ \\
\hline 4 year swap rate & $0.6201 \%$ \\
\hline 5 year swap rate & $0.8194 \%$ \\
\hline 6 year swap rate & $1.0537 \%$ \\
\hline 7 year swap rate & $1.2738 \%$ \\
\hline 8 year swap rate & $1.4678 \%$ \\
\hline 9 year swap rate & $1.6360 \%$ \\
\hline 10 year swap rate & $1.7825 \%$ \\
\hline 12 year swap rate & $2.0334 \%$ \\
\hline 15 year swap rate & $2.2783 \%$ \\
\hline 20 year swap rate & $2.4782 \%$ \\
\hline 25 year swap rate & $2.5790 \%$ \\
\hline 30 year swap rate & $2.6422 \%$ \\
\hline
\end{tabular}

The equity information and recovery rates are provided in Table 3. To determine hazard rates, we need to know the observed market prices of corporate bonds or CDS premia, as the market standard practice is to fit the implied risk-neutral default intensities to these credit sensitive instruments. The corporate bond prices are unfortunately not available for companies $X$ and $Y$, but their CDS premia are observable as shown in Table 4. Usually the CDS market leads the bond market, in particular during crisis situation. Liquidity 
in the bond market is typically drying up during a financial crisis. Demand for insurance against default risk, on the other hand, increases if the issuer is experiencing financial stress. Consequently, prices and spreads derived from the CDS market tend to be more reliable. Said differently, CDSs on reference entities are often more actively traded than bonds issued by the reference entities.

Unlike other studies that use bond spreads for pricing (see Tsiveriotis and Fernandes (1998), Ammann, et al. (2003), Zabolotnyuk, et al. (2010), etc.), we perform risky valuation based on credit information extracted from CDS spreads. Given the recovery rates and the CDS premia, we can compute the hazard rates via a standard calibration process (see J.P. Morgan (2001)).

\section{Table 3. Equity and recovery information}

This table displays the closing stock prices and dividend yields on September 10, 2012, as well as the recovery rates

\begin{tabular}{|c|c|c|}
\hline & Company X & Company Y \\
\hline Stock price & 34.63 & 23.38 \\
Dividend yield & $2.552 \%$ & $3.95 \%$ \\
Bond recovery rate & $40 \%$ & $36.14 \%$ \\
Equity recovery rate & $2 \%$ & $1 \%$ \\
\hline
\end{tabular}

Table 4. CDS premia

This table displays the closing CDS premia as of September 10, 2012.

\begin{tabular}{|c|c|c|}
\hline Name & Company X & Company Y \\
\hline 6 month CDS spread & 0.00324 & 0.01036 \\
1 year CDS spread & 0.00404 & 0.01168 \\
2 year CDS spread & 0.00612 & 0.01554 \\
3 year CDS spread & 0.00825 & 0.01924 \\
4 year CDS spread & 0.01027 & 0.02272 \\
5 year CDS spread & 0.01216 & 0.02586 \\
7 year CDS spread & 0.01388 & 0.02851 \\
10 year CDS spread & 0.01514 & 0.03003
\end{tabular}




\begin{tabular}{|l|l|l|}
15 year CDS spread & 0.01544 & 0.03064 \\
20 year CDS spread & 0.01559 & 0.03101 \\
\hline
\end{tabular}

The most important input parameter to be determined is the volatility for valuation. A common approach in the market is to use the at-the-money (ATM) implied Black-Scholes volatility to price convertible bonds. For the 5-year outstanding convertible bond (case 1 in Table 1), we find the ATM implied Black-Scholes volatility is $31.87 \%$, and then price the convertible bond accordingly. The results are shown in Table 5. Our analysis actually indicates an overpricing of $0.42 \%$.

For the 17-year outstanding convertible bond (case 2 in Table 1), however, most liquid stock options have relatively short maturates (rarely more than 8 years). Therefore, some authors, such as Ammann, et al. (2003), Loncarski, et al. (2009), Zabolotnyuk, et al. (2010), have to make do with historical volatilities. Similarly, we calculate the historical volatility as the annualized standard deviation of the daily $\log$ returns of the last 2 years (from September 10, 2010 to September 10, 2012), and then value the convertible bond based on this real-world volatility. The result shown in Table 5 reports an underpricing of $1.07 \%$. The test results demonstrate that the model prices are very close to the market prices, indicating that the model is quite accurate.

\section{Table 5. Model price vs. market price}

This table shows the differences between the model prices and the market prices of the convertible bonds under different volatility assumptions, where Difference $=($ Model price $) /($ Market observed price $)-1$. The convertible bonds are defined in Table 1.

\begin{tabular}{|c|c|c|}
\hline & Case 1 (a 7-year convertible) & Case 2 (a 20-year convertible) \\
\hline Type of volatility & ATM implied Black-Scholes volatility & Annualized historical volatility \\
Value of volatility & $31.87 \%$ & $18.07 \%$ \\
Model price & 134.32 & 171.58 \\
Market observed price & 134.88 & 169.77 \\
Difference & $-0.42 \%$ & $1.07 \%$ \\
\hline
\end{tabular}


We repeat this exercise for all contracts on all observation days. For any short-maturity convertible bond, we use the ATM implied Black-Scholes volatility for pricing, whereas for any long-maturity convertible bond, we perform valuation via the historical volatility. The results are presented in Tables 6 .

\section{Table 6. Statistics of underpricing for different maturity classes}

An observation corresponds to a price snapshot of a convertible bond at a certain valuation date. Underpricing is referred to as the model price minus the market price.

\begin{tabular}{|c|c|cccc|}
\hline \multirow{2}{*}{ Maturity } & \multirow{2}{*}{ Observations } & \multicolumn{4}{|c|}{ Underpricing } \\
\cline { 3 - 5 } & & Mean (\%) & Std (\%) & Max (\%) & Min (\%) \\
\hline$\leq 8$ years & 82998 & -0.13 & 1.37 & 0.79 & -1.08 \\
$>8$ years & 2610 & 1.67 & 2.03 & 2.24 & 0.58 \\
\hline
\end{tabular}

Next, our sample is partitioned into subsamples according to the moneyness of convertibles. The moneyness is measured by the ratio of the conversion value to the equivalent straight bond value or the investment value. The underpricing of each daily observation with respect to the degree of moneyness is shown in Table 7, where moneyness between 0 and 0.9 corresponds to out-of-the-money; moneyness between 0.9 and 1.1 represents around-the-money; and moneyness higher than 1.1 is related to in-themoney.

\section{Table 7. Statistics of underpricing for different moneyness classes}

The moneyness is measured by dividing the conversion value through the associated straight bond value. An observation corresponds to a snapshot of the market used to price a convertible bond at a certain valuation date.

\begin{tabular}{|c|c|c|c|}
\hline \multirow{2}{*}{ Moneyness } & \multirow{2}{*}{ Observations } & \multicolumn{2}{|c|}{ Underpricing } \\
\cline { 3 - 4 } & & Mean (\%) & Std (\%) \\
\hline$<0.5$ & 5794 & 0.72 & 2.23 \\
$0.5-0.7$ & 10595 & -0.87 & 2.37 \\
\hline
\end{tabular}




\begin{tabular}{|c|c|c|c|}
$0.7-0.9$ & 19850 & 0.51 & 1.64 \\
$0.9-1.1$ & 14737 & 0.45 & 1.12 \\
$1.1-1.3$ & 14379 & -0.55 & 1.89 \\
$1.3-1.5$ & 11631 & -0.42 & 2.04 \\
$>1.5$ & 8622 & -0.62 & 1.72 \\
\hline
\end{tabular}

From Tables 7, it can be seen that the model prices fluctuate randomly around the market prices (sometimes overpriced and sometimes underpriced), indicating the model is quite accurate. Empirically, we do not find support for presence of a systematic underpricing as indicated in previous studies (see Carayannopoulos and Kalimipalli (2003), Ammann, et al. (2003), etc.). If there is no underpricing, how has the arbitrage strategy been successful in the past? Maybe convertible arbitrage is not solely based on underpricing

In a typical convertible bond arbitrage strategy, the arbitrageur entails purchasing a convertible bond and selling the underlying stock to create a delta neutral position. The number of shares sold short usually reflects a delta-neutral or market neutral ratio. It is well known that delta neutral hedging not only removes small directional risks but also is capable of making a profit on an explosive upside or downside breakout if the position's gamma is kept positive. As such, delta neutral hedging is great for uncertain stocks that are expected to make huge breakouts in either direction. Since convertible bonds are issued mainly by start-up or small companies, the chance of a large movement in either direction is very likely. Even for very small movements in the underlying stock price, profits can still be generated from the yield of the convertible bond and the interest rebate for the short position.

We calculate the delta and gamma values for the two deals described in table 1 . The Greeks vs. spot equity prices are plotted in Figures $2 \sim 5$. It can be seen that the deltas increase with the underlying stock prices in Figures 2 and 4. At low market levels, the convertibles behave like their straight bonds with very small deltas. As the stock price increases, conversion becomes more likely. At certain market levels the convertibles are certain to be converted. In this case, the convertibles are similar to the underlying equities and the deltas are equal to the number of shares (i.e., conversion ratios). 
Figure 2. Delta vs. underlying price for a 7-year convertible bond

This graph shows how the delta of the 7-year convertible bond (described in Table 1) changes as the underlying stock price changes.

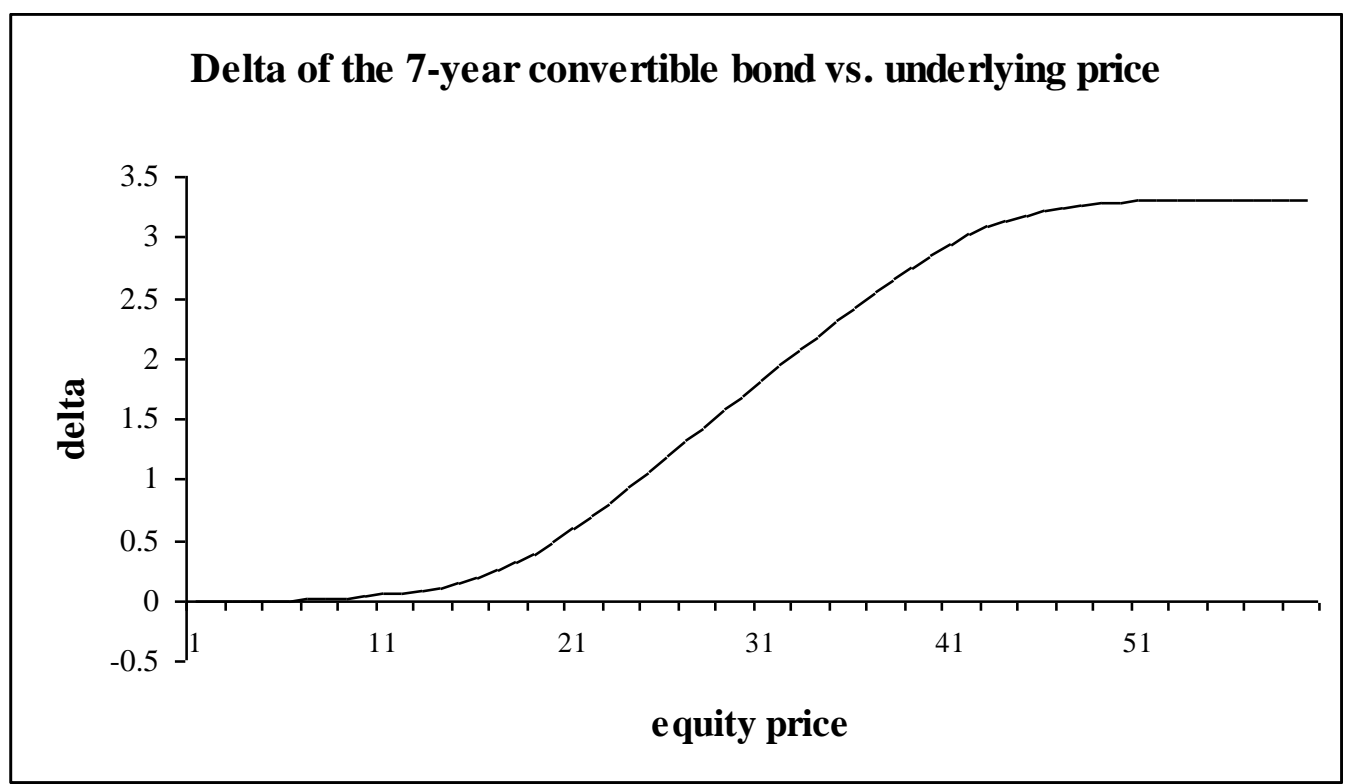

Figure 3. Gamma vs. underlying price for a 7-year convertible bond

This graph shows how the gamma of the 7-year convertible bond (described in Table 1) changes as the underlying stock price changes. 


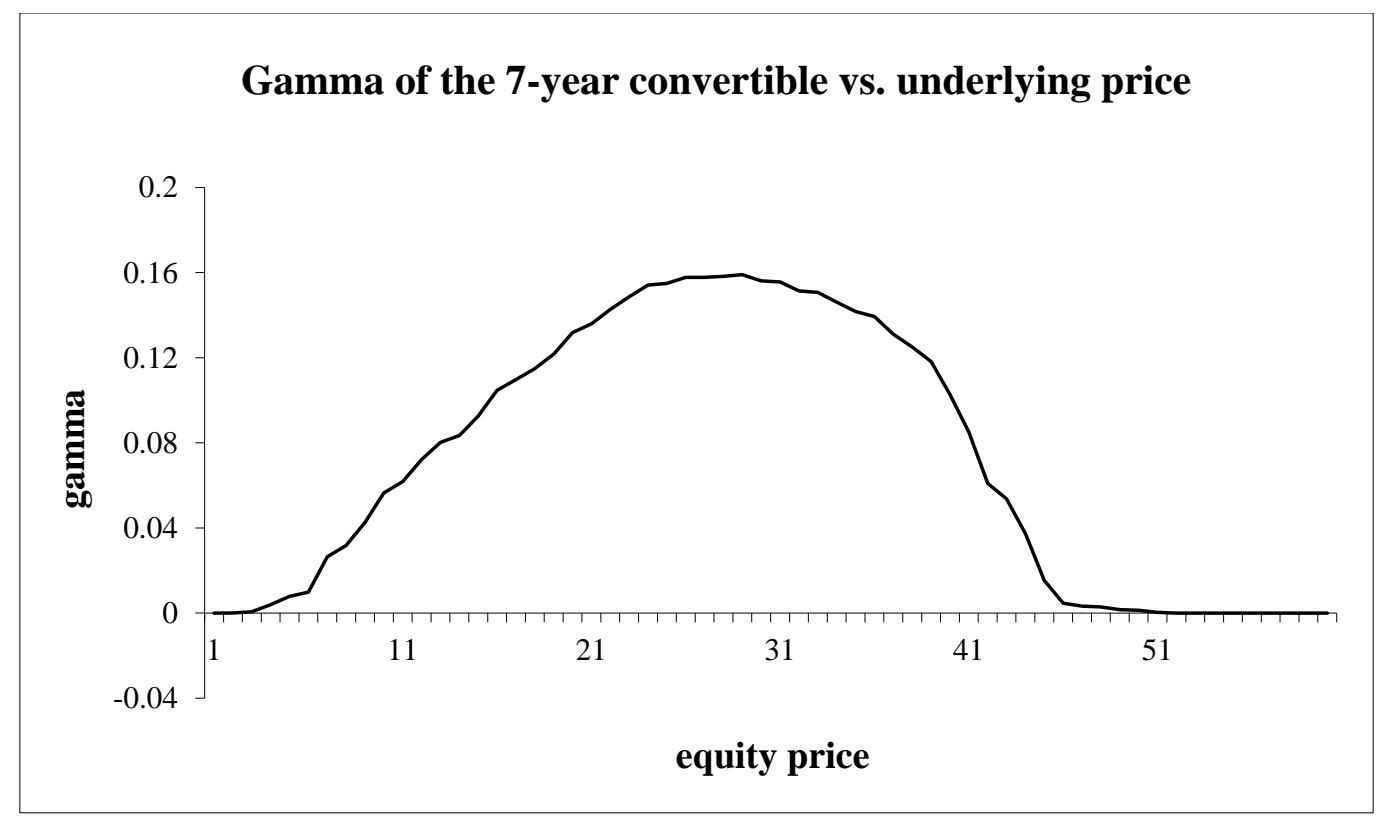

Figure 4. Delta vs. underlying price for a 20-year convertible bond

This graph shows how the delta of the 20 -year convertible bond (described in Table 1) changes as the underlying stock price changes.

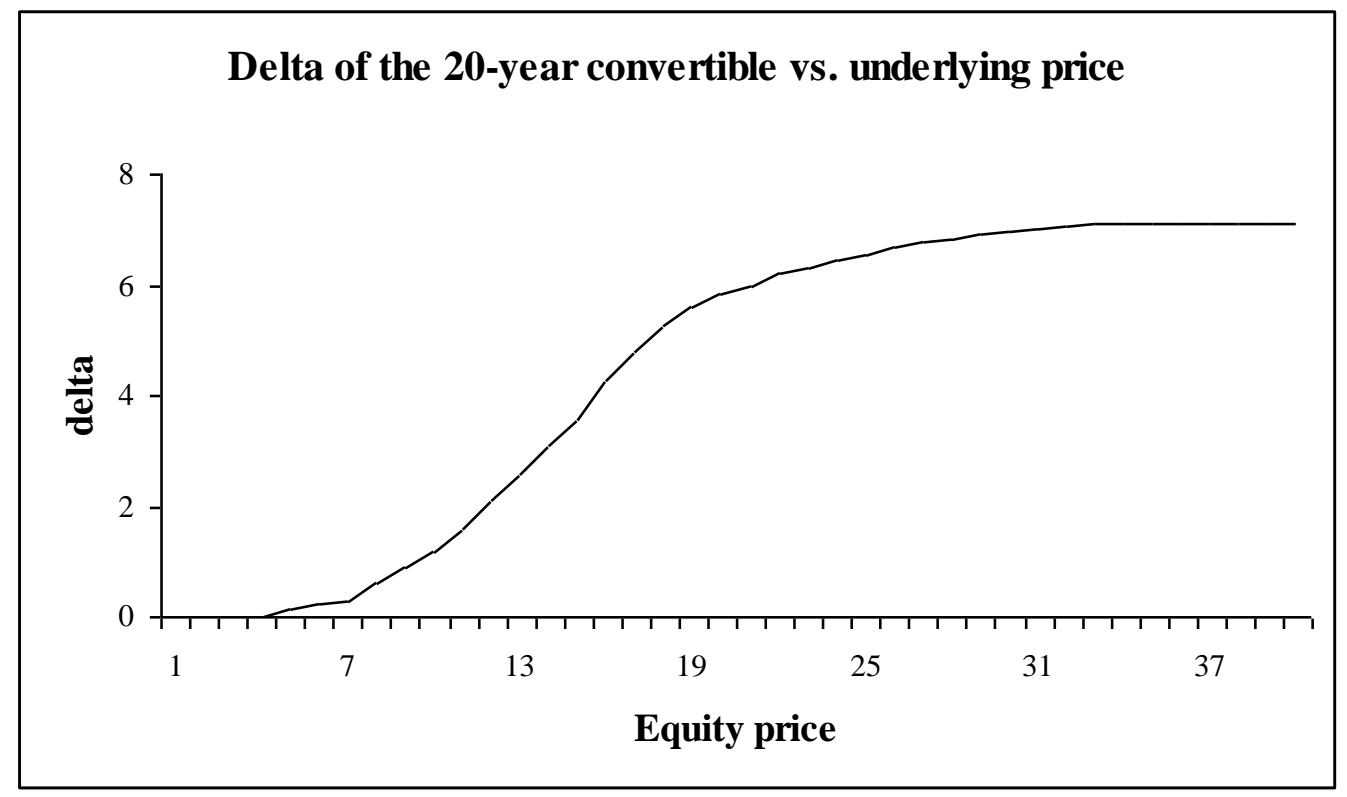

Figure 5. Gamma vs. underlying price for a 20 -year convertible bond 
This graph shows how the delta of the 20-year convertible bond (described in Table 1) changes as the underlying stock price changes.

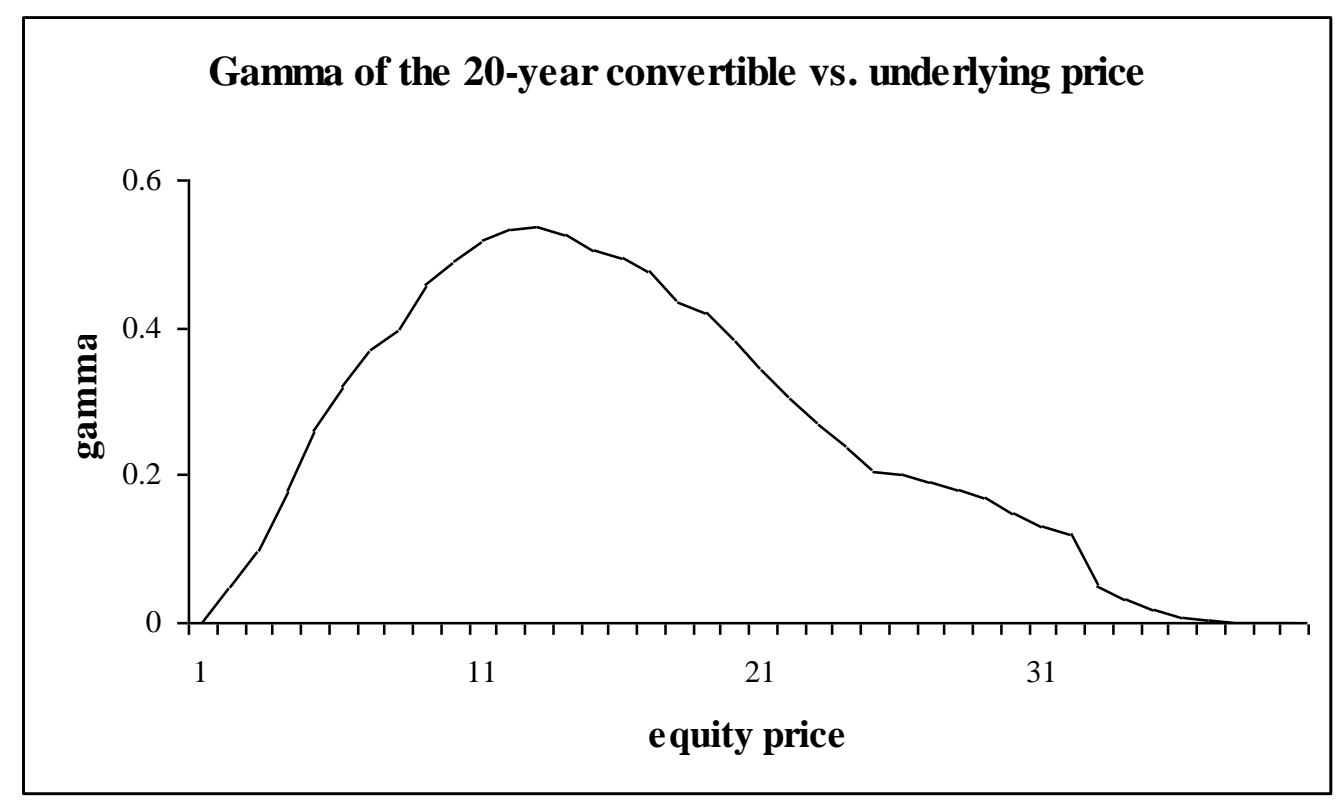

The gamma diagrams in Figures 3 and 5 have a frown shape. The gammas are the highest when the convertibles are at-the-money. It is intuitive that when the stock prices rise or fall, profits increase because of favorably changing deltas. For this reason, convertible bonds are very good candidates for delta neutral hedging. Relatively large positive gammas of convertibles could be one of the main drivers of profitability in convertible arbitrage.

\section{Conclusion}

This paper aims to value hybrid financial instruments (e.g., convertible bonds) whose values may simultaneously depend on different assets subject to credit risk in a proper and consistent way. The motivation for our model is that if a company goes bankrupt, all the securities (including the equity) of the company default. The recovery is realized in accordance with the priority established by the Bankruptcy Code. In other words, different securities have the same probability of default, but different recovery rates. 
Our study shows that risky asset pricing is quite different from risk-free asset pricing. In fact, the expectation of a defaultable asset actually grows at a risky rate rather than the risk-free rate. This conclusion is very important for risky valuation.

We propose a hybrid framework to value risky equities and debts in a unified way. The model relies on the probability distribution of the default jump rather than the default jump itself. The model is quite accurate for pricing convertible bonds.

Empirically, we do not find evidence supporting a systematic underpricing hypothesis. We also find that convertible bonds have relatively large positive gammas, implying that convertible arbitrage can make a profit on a large upside and downside movement in the underlying stock price.

\section{Appendix}

\section{A. Numeric implementation for PDE}

In this section, we describe the numerical method used to solve discrete forms of (23) and (28). Let

$x=\ln \left(\frac{S_{t}}{S_{0}}\right)$ and define backward time as $\delta=T-t$. The equations (23) and (28) can be rewritten as

$$
\begin{aligned}
& \frac{\partial B}{\partial \delta}-\frac{1}{2} \sigma^{2} \frac{\partial^{2} B}{\partial x^{2}}-\left(r-q+h\left(1-\varphi_{s}\right)-\frac{\sigma^{2}}{2}\right) \frac{\partial B}{\partial x}+\left(r+h\left(1-\varphi_{b}\right)\right) B=0 \\
& \frac{\partial G}{\partial \delta}-\frac{1}{2} \sigma^{2} \frac{\partial^{2} G}{\partial x^{2}}-\left(r-q+h\left(1-\varphi_{s}\right)-\frac{\sigma^{2}}{2}\right) \frac{\partial G}{\partial x}+\left(r+h\left(1-\varphi_{s}\right)\right) G=0
\end{aligned}
$$

The equations (A1) and (A2) can be approximated using Crank-Nicolson rule. We discretize the $x$ to be equally spaced as a grid of nodes $0 \sim M$. At the maturity, $G_{T}$ and $B_{T}$ are determined according to (29) and (30). At any time $i+1$, the boundary conditions are

$$
\begin{gathered}
\left\{\begin{array}{c}
B_{0}^{i+1}\left(1+0.5\left(r+h\left(1-\varphi_{b}\right) \Delta \tau\right)=B_{0}^{i}\left(1-0.5\left(r+h\left(1-\varphi_{b}\right)\right) \Delta \tau\right)\right. \\
G_{0}^{i+1}\left(1+0.5\left(r-q+h\left(1-\varphi_{s}\right) \Delta \tau\right)=G_{0}^{i}\left(1-0.5\left(r-q+h\left(1-\varphi_{s}\right)\right) \Delta \tau\right)\right.
\end{array}\right. \\
\left\{\begin{array}{c}
B_{M}^{i+1}=0 \\
G_{M}^{i+1}=\eta S_{M}
\end{array} \quad \text { when } x \approx 0\right.
\end{gathered}
$$


Then, we conduct the backward induction. The procedure is as follows.

For $\mathrm{i}=$ penultimateTime to currentTime

// determine accrual interest and call/put prices

// determine boundary nodes

// use the PSOR (Projected Successive Over Relaxation) method to obtain the continuation value of the bond component $\tilde{B}_{t}$ and the continuation value of the equity component $\tilde{G}_{t}$, applying the constraints (31).

\section{EndFor}

The value at node[0][y] is the convertible bond price where the equity price at node[0][y] is equal to the current market stock price.

\section{B. Binomial tree algorithm}

A binomial tree method is equivalent to an explicit difference scheme. Suppose that the stock price $S$ will either move up to the value $u S$ with probability $p_{u}$ or down to the value $d S$ with probability $p_{d}=1-p_{u}$. As the binomial tree is a discrete approximation to the continuous distribution of equation (16), the expectation and variance of the discrete distribution should be equal to those of the continuous distribution. This method is commonly referred to as the moment matching technique.

To match the expectation, we have

$$
E\left(S\left(t_{i+1}\right) / S\left(t_{i}\right)\right)=p_{u} S\left(t_{i}\right) u+\left(1-p_{u}\right) S\left(t_{i}\right) d=S\left(t_{i}\right) \exp \left(y_{s} \Delta t\right)
$$

or

$$
p_{u} u+\left(1-p_{u}\right) d=\exp \left(y_{s} \Delta t\right)
$$

where

$$
y_{s}=r-q+c_{s}=r-q+h\left(1-\varphi_{s}\right)
$$

where $q$ is the dividend.

To match the variance, we get 


$$
\operatorname{Var}\left(S\left(t_{i+1}\right) / S\left(t_{i}\right)\right)=S^{2}\left(t_{i}\right)\left[p_{u} u^{2}+\left(1-p_{u}\right) d^{2}-\exp \left(2 y_{s} \Delta t\right)\right]=S^{2}\left(t_{i}\right) \exp \left(2 y_{s} \Delta t\right)\left(\exp \left(\sigma^{2} \Delta t\right)-1\right)
$$

or

$$
p_{u} u^{2}+\left(1-p_{u}\right) d^{2}=\exp \left(2 y_{s} \Delta t\right) \exp \left(\sigma^{2} \Delta t\right)
$$

Solving equations (B2) and (B5) according to the usual tree-symmetry condition: $u=1 / d$, we obtain

$$
\begin{gathered}
p_{u}=\frac{\exp \left(y_{s} \Delta t\right)-d}{u-d} \\
u=\frac{\exp \left(2 y_{s} \Delta t\right) \exp \left(\sigma^{2} \Delta t\right)+1+\sqrt{\left(\exp \left(2 y_{s} \Delta t\right) \exp \left(\sigma^{2} \Delta t\right)+1\right)^{2}-4 \exp \left(2 y_{s} \Delta t\right)}}{2 \exp \left(y_{s} \Delta t\right)} \\
d=\frac{\exp \left(2 y_{s} \Delta t\right) \exp \left(\sigma^{2} \Delta t\right)+1-\sqrt{\left(\exp \left(2 y_{s} \Delta t\right) \exp \left(\sigma^{2} \Delta t\right)+1\right)^{2}-4 \exp \left(2 y_{s} \Delta t\right)}}{2 \exp \left(y_{s} \Delta t\right)}
\end{gathered}
$$

There are many ways to approximate equations (B7) and (B8). The most well-known one is the Cox, Ross, and Rubinstein (1979) type approximation that is up to order $\Delta t$ accuracy and is given by

$$
\begin{gathered}
u=\exp (\sigma \sqrt{\Delta t}) \\
d=\exp (-\sigma \sqrt{\Delta t})
\end{gathered}
$$

Equations (B6), (B9) and (B10) specify the binomial risky tree parameters that are used to map the continuous stock price dynamics into the lattice representation.

Suppose that there is a convertible bond. Let us construct a trading strategy $H=(\alpha, \beta)$ to hold $\alpha$ units of the risky stock and $\beta$ units of the risky bond. At time $t_{i}$ the convertible bond value is $C\left(t_{i}\right)=C_{B}\left(t_{i}\right)+C_{S}\left(t_{i}\right)$ where $C_{B}\left(t_{i}\right)$ is the bond component and $C_{S}\left(t_{i}\right)$ is the stock component; the stock value is $S\left(t_{i}\right)$; and the bond value is $B\left(t_{i}\right)$. At time $t_{i+1}$, the bond value becomes $B\left(t_{i}\right) \exp \left(y_{b} \Delta t\right)$ where $y_{b}=r+h\left(1-\varphi_{b}\right)$ is the risky rate of the bond; the stock value becomes either $u S\left(t_{i}\right)$ or $d S\left(t_{i}\right)$; and the convertible value has two possible outcomes: $C^{u}\left(t_{i+1}\right)=C_{B}^{u}\left(t_{i+1}\right)+C_{E}^{u}\left(t_{i+1}\right)$ or $C^{d}\left(t_{i+1}\right)=C_{B}^{d}\left(t_{i+1}\right)+C_{E}^{d}\left(t_{i+1}\right)$ 
corresponding to either an up movement or a down movement in the stock price. The discounted portfolio should replicate the discounted convertible bond ${ }^{5}$, which yields

$$
\begin{aligned}
& \alpha_{i+1} u S\left(t_{i}\right) \exp \left(-y_{s} \Delta t\right)+\beta_{i+1} B\left(t_{i}\right)=C_{B}^{u}\left(t_{i+1}\right) \exp \left(-y_{b} \Delta t\right)+C_{S}^{u}\left(t_{i+1}\right) \exp \left(-y_{s} \Delta t\right) \\
& \alpha_{i+1} d S\left(t_{i}\right) \exp \left(-y_{s} \Delta t\right)+\beta_{i+1} B\left(t_{i}\right)=C_{B}^{d}\left(t_{i+1}\right) \exp \left(-y_{b} \Delta t\right)+C_{S}^{d}\left(t_{i+1}\right) \exp \left(-y_{s} \Delta t\right)
\end{aligned}
$$

Solving for $\alpha_{i+1}, \beta_{i+1}$ yields

$$
\begin{gathered}
\alpha_{i+1}=\frac{C_{S}^{u}\left(t_{i+1}\right)-C_{S}^{d}\left(t_{i+1}\right)}{S\left(t_{i}\right)(u-d)}+\frac{C_{B}^{u}\left(t_{i+1}\right)-C_{B}^{d}\left(t_{i+1}\right)}{S\left(t_{i}\right)(u-d)} \exp \left(y_{s} \Delta t-y_{b} \Delta t\right) \\
\beta_{i+1}=\frac{u C_{S}^{d}\left(t_{i+1}\right)-d C_{S}^{u}\left(t_{i+1}\right)}{B\left(t_{i}\right)(u-d)} \exp \left(-y_{s} \Delta t\right)+\frac{u C_{B}^{d}\left(t_{i+1}\right)-d C_{B}^{u}\left(t_{i+1}\right)}{B\left(t_{i}\right)(u-d)} \exp \left(-y_{b} \Delta t\right)
\end{gathered}
$$

For a self-financing portfolio, the initial wealth needed to finance this strategy (sometimes called the manufacturing cost of the contingent claim) is

$$
\begin{aligned}
C\left(t_{i}\right) & =C_{B}\left(t_{i}\right)+C_{S}\left(t_{i}\right)=\alpha_{i+1} S\left(t_{i}\right)+\beta_{i+1} B\left(t_{i}\right) \\
& =\left[p_{u} C_{S}^{u}\left(t_{i+1}\right)+\left(1-p_{u}\right) C_{S}^{d}\left(t_{i+1}\right)\right] \exp \left(-y_{s} \Delta t\right)+\left[p_{u} C_{B}^{u}\left(t_{i+1}\right)+\left(1-p_{u}\right) C_{B}^{d}\left(t_{i+1}\right)\right] \exp \left(-y_{b} \Delta t\right)
\end{aligned}
$$

where $p_{u}$ is defined in (B6).

We split equation (B15) into an equity equation and a bond equation, and get

$$
\begin{gathered}
C_{S}\left(t_{i}\right)=\left\lfloor p_{u} C_{S}^{u}\left(t_{i+1}\right)+\left(1-p_{u}\right) C_{S}^{d}\left(t_{i+1}\right)\right\rfloor \exp \left(-y_{s} \Delta t\right) \\
C_{B}\left(t_{i}\right)=\left\lfloor p_{u} C_{B}^{u}\left(t_{i+1}\right)+\left(1-p_{u}\right) C_{B}^{d}\left(t_{i+1}\right)\right\rfloor \exp \left(-y_{b} \Delta t\right)
\end{gathered}
$$

Equations (B16) and (B17) tell us that the fair price of an equity component or a bond component is equal to the expected value of its future payoffs discounted by the associated risky rate. The expected value is calculated using the corresponding values from the latter two nodes (up or down) weighted by the transition probabilities.

\footnotetext{
${ }^{5}$ Unlike the risk-free tree, the risky tree tries to match the discounted value of the replicating portfolio to the discounted value of the convertible bond in order to catch credit risk properly.
} 


\section{A comparison of results}

Let us now briefly turn to a comparison with previous works. We use a simple example described in Table C1, which is similar to the example used in Tsiveriotis and Fernandes (1998) and Ayache, et al. (2003). We assume that the interest rate, the bond spread, and the volatility are flat. The hazard rate is $0.02 /(1-0)=0.02$. As the call and put prices are quoted using the clean prices, we need to convert them to the dirty prices as

$$
P^{\text {dirty }}(t)=P^{\text {clean }}(t)+A I(t)
$$

where the accrued interest is give by

$$
A I(t)=C \frac{\delta\left(t, t_{s}\right)}{\delta\left(t_{e}, t_{s}\right)}
$$

where $\mathrm{C}$ denotes the coupon, $\delta\left(t_{s}, s_{e}\right)$ denotes the accrual factor or day count fraction for period $\left(t_{s}, t_{e}\right)$ where $t_{s} \leq t \leq t_{e}, t_{s}$ denotes the start time of the accrual period, and $t_{e}$ denotes the end time of the accrual period. The numerical results are shown in Table C2, from which we can see that our model generates lower results than AVF and TF models.

Table C1. A 5-year convertible bond

\begin{tabular}{|l|l|}
\hline Maturity & 5 years \\
Payment frequency & Semiannual \\
Notional & 4 \\
Conversion rule & 100 \\
Clean call price & 1 share (ratio) in $0-5$ years \\
Clean put price & 110 in $2-5$ years \\
Spot stock price & 105 at 3 years \\
Implied volatility of the convertible & 100 \\
Interest rate & 0.2 \\
Bond spread & 0.05 \\
\end{tabular}




\begin{tabular}{|l|l|} 
Bond recovery rate & 0 \\
Stock recovery rate & 0 \\
\hline
\end{tabular}

\section{Table C2. Model comparison results}

This table presents the numerical results for model comparison. The Tsiveriotis and Fernandes (1998) model is referred to as the TF model and the Ayache, et al. (2003) model is referred to as the AFV model. The convertible bond is described in Table $\mathrm{C} 1$.

\begin{tabular}{|l|l|l|l|}
\hline Time steps & This model & AFV & TF \\
\hline 200 & 122.6921 & 122.7341 & 124.0025 \\
400 & 122.6938 & 122.7333 & 123.9916 \\
800 & 122.6961 & 122.7325 & 123.9821 \\
1600 & 122.6953 & 122.7319 & 123.9754 \\
3200 & 122.6952 & 122.7316 & 123.9714 \\
\hline
\end{tabular}

\section{References}

Agarwal, V., W. Fung, Y. Loon and N. Naik, (2007), "Liquidity provision in the convertible bond market: analysis of convertible arbitrage hedge funds," CFR-working paper, Georgia State University.

Ammann, M., Kind, A., and Wilde, C., (2003), “Are convertible bonds underpriced? An analysis of the French market,” Journal of Banking \& Finance Vol. 27, No. 4, pp. 635-653.

Ammann, M, Kind, A., and Wilde, C., (2008), “Simulation-based pricing of convertible bonds," Journal of empirical finance, Vol. 15, No. 2, pp. 310-331.

Andersen, L. and Buffum, D., (2004), "Calibration and implementation of convertible bond models," Journal of Computational Finance, Vol. 7, No. 4, pp. 1-34. 
Ayache, E., Forsyth, P. A., and Vetzal, K. R., (2003), "The valuation of convertible bonds with credit risk," Journal of Derivatives, Vol. 11, No. 1, pp. 9-30.

Batta, George, George Chacko, and Bala G. Dharan, (2010), "Valuation consequences of convertible debt issuance,” Journal of Fixed Income, Vol. 20, No. 1, pp. 28-43.

Bloomberg, (2009), “OVCV model description,” Quantitative research and development, Equities team.

Brennan, M. and Schwartz, E., (1980), “Analyzing convertible bonds," Journal of Financial and Quantitative Analysis, Vol. 15, No. 4, pp. 907-929.

Calamos, Nick P., (2011), Convertible arbitrage: Insights and techniques for successful hedging, John Wiley \& Sons.

Carr, P. and Linetsky, V., (2006), “A jump to default extended CEV model: an application of Bessel processes," Finance and Stochastics, Vol. 10, No. 3, pp. 303-330.

Carayannopoulos, P. and Kalimipalli, M., (2003), “Convertible bond prices and inherent biases,” Journal of Fixed Income, Vol. 13, No. 3, pp. 64-73.

Chen, N. and S. Kou, (2009), "Credit spreads, optimal capital structure, and implied volatility with endogenous default and jump risk," Mathematical Finance, Vol. 19, No. 2, pp. 343-378.

Choi, D., Getmansky, M. and Tookes, H., (2009), “Convertible bond arbitrage, liquidity externalities, and stock prices," Journal of Financial Economics, Vol. 91, No. 2, 227-251. 
Cox, J., S. Ross, and M. Rubinstein, (1979), "Option Pricing: A Simplified Approach." Journal of Financial Economics, Vol. 7, No. 3, pp. 229-263.

Davis, M. and Lischka, F. R., (1999), “Convertible bonds with market risk and credit risk,” Working paper, Tokyo-Mitsubishi International plc.

Duffie, D., and Huang, M., (1996), "Swap rates and credit quality," Journal of Finance, Vol. 51, No. 3, pp. 921-949.

Duffie, D., and Singleton, K. J., (1999), "Modeling term structure of defaultable bonds," Review of Financial Studies, Vol. 12, No. 4, pp. 687-720.

Ederington, L. and H. Lee, (1993), "How markets process information: News releases and volatility," Journal of Finance, Vol. 48, No. 4, pp. 1161-1191.

FinPricing, 2015, Debt Trading Solution, https://finpricing.com/lib/IrBasisCurve.html

Grimwood, R., and Hodges, S., (2002), The valuation of convertible bonds: a study of alternative pricing models, Working paper, Warwick University.

Goldman Sachs, (1994), "Valuing convertible bonds as derivatives," Quantitative Strategies Research Notes, Goldman Sachs.

Hilberink, B. and L. Rogers, (2002), “Optimal capital structure and endogenous default," Finance Stochastics, Vol. 6, No. 2, pp. 237-263. 
Hull, J., (2003), Options, Futures and Other Derivatives. 5th ed. Prentice Hall, Upper Saddle River, NJ.

Jarrow, R. A., and Protter, P., (2004), "Structural versus reduced form models: a new information based perspective," Journal of Investment Management, Vol. 2, No. 2, pp. 34-43.

Loncarski, I., Horst, J., and Veld C., (2009), "The rise and demise of the convertible arbitrage strategy," Financial Analysts Journal, Vol. 65, No. 5, pp. 35-50.

Merton, R. C., (1976), “Option pricing when underlying stock returns are discontinuous,” Journal of Financial Economy, Vol. 3, No. 1-2, pp. 125-144.

J. P. Morgan, (1999), “The J. P. Morgan guide to credit derivatives,” Risk Publications.

J.P. Morgan, (2001), "Par credit default swap spread approximation from default probabilities," Risk Publications.

Somanath, V.S., (2011), International financial management, I.K. International Publishing House Pvt. Ltd.

Tsiveriotis, K. and Fernandes, C., (1998), "Valuing convertible bonds with credit risk,” Journal of Fixed Income, Vol. 8, No. 4, pp. 95-102.

Xiao, T., (2013), “An accurate solution for credit value adjustment (cva) and wrong way risk," Working paper, SSRN.

Zabolotnyuk, Y., Jones, R., and Veld, C., (2010), “An empirical comparison of convertible bond valuation models," Financial Management, Vol. 39, No. 2, pp. 675-705. 
Zhou, C., (1997), “A jump-diffusion approach to modeling credit risk and valuing defaultable securities," Technical Report, Federal Research Board, Washington DC. 